\title{
Leptin Is Not Essential for Obesity-Associated Hypertension
}

\author{
Julia von Schnurbein ${ }^{\mathrm{a}} \quad$ Jaida Manzoor ${ }^{\mathrm{b}}$ Stephanie Brandt ${ }^{\mathrm{a}}$ \\ Friederike Denzer $^{a} \quad K^{2}$ atja Kohlsdorfa ${ }^{a}$ Pamela Fischer-Posovszky ${ }^{a}$ \\ Mario Weißenberger ${ }^{a}$ Sabine Frank-Podlech ${ }^{c-e}$ Saqib Mahmood ${ }^{f}$ \\ Martin Wabitsch ${ }^{a}$ \\ ${ }^{a}$ Division of Pediatric Endocrinology and Diabetes, Ulm University Hospital, Ulm, Germany; \\ ' $T$ The Children's Hospital and Institute of Child Health, Lahore, Pakistan; ' Institute of Medical \\ Psychology and Behavioral Neurobiology, University of Tübingen, Tübingen, Germany; \\ ${ }^{d}$ Institute for Diabetes Research and Metabolic Diseases of the Helmholtz Center Munich \\ at the University of Tübingen, German Center for Diabetes Research (DZD), Tübingen,

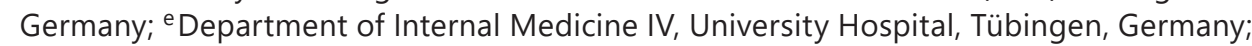 \\ ${ }^{f}$ Department of Human Genetics and Molecular Biology, University of Health Sciences \\ Lahore, Lahore, Pakistan
}

\section{Keywords}

Hypertension · Leptin · Genetics · Metabolism · Mutation · Obesity

\begin{abstract}
Background and Objective: Hyperleptinemia is supposed to play a causal role in the development of obesity-associated hypertension, possibly via increased sympathetic tone. Hence patients with congenital leptin deficiency should be hypotensive and their low blood pressure should increase under leptin substitution. Subjects and Methods: To test this assumption, we examined ambulatory blood pressure, resting heart rate, Schellong test results, cold pressor test results, heart rate variability, catecholamine metabolites, and aldosterone levels in 6 patients with congenital leptin deficiency before as well as 2-7 days and 7-14 months after the start of leptin substitution. Ambulatory blood pressure was also examined in 3 patients with biallelic disease-causing variants in the leptin receptor gene. Results: Contrary to our expectations, even before leptin substitution, 1 patient with biallelic leptin receptor gene variants and 4 patients with leptin deficiency had been suffering from hypertension. Short-term substitution with leptin increased blood pressure further in 3 out of 4 patients (from $127.0 \pm 11.7$ to $133.8 \pm 10.6 \mathrm{~mm} \mathrm{Hg}$ ), concomitant with an increase in resting heart rate as well as in heart rate during the Schellong test in all patients (from $87.6 \pm 7.7$ to $99.9 \pm 11.0 \mathrm{bpm}, p=0.031$, and from $102.9 \pm 13.5$ to $115.6 \pm 11.3 \mathrm{bpm}, p=0.031$, respectively). Furthermore, the systolic blood pressure response during the cold pressor test increased in 4 out of 6 patients. Unexpectedly, catecholamine metabolites and aldosterone levels did not increase. After long-term leptin substitution and weight loss, the resting heart rate decreased in 4 out of 6 patients
\end{abstract}


compared to baseline, and in all patients below the heart rate seen immediately after the start of therapy (from $99.9 \pm 11.0$ to $81.7 \pm 5.4 \mathrm{bpm} ; p=0.031$ ). Conclusions: These results show that obesity-associated hypertension does not depend on the presence of leptin. However, short-term leptin substitution can increase the blood pressure and heart rate in obese humans with leptin deficiency, indicating that leptin plays at least an additive role in obesity-associated hypertension. The mechanisms behind this are not clear but might include an increase in regional sympathetic tone.

(C) 2019 The Author(s)

Published by S. Karger AG, Basel

\section{Introduction}

Along with the epidemic of obesity, obesity-related comorbidities have risen considerably as well. One major concern is obesity-associated hypertension, which is an important cause of cardiovascular morbidity and mortality [1].

Various mechanisms leading to the obesity-associated increase in blood pressure have been suggested, including mechanical compression of the kidney [2], endothelial dysfunction [3], overactivation of the renin-angiotensin system [4], elevation of aldosterone levels [5], and increased sympathetic tone [6,7]. Despite intensive research, it is not fully clear how obesity triggers these changes. Several population studies have indicated that obesity-induced hyperleptinemia might be an important mediator of some of these pathogenic processes, as leptin levels have been shown to correlate closely to blood pressure [8, 9].

Leptin is an adipocyte-derived, circulating hormone with various endocrine and paracrine effects mediated via a specific leptin receptor. Leptin levels depend on the nutritional status, with higher plasma levels in obese persons than in lean subjects [10]. The most prominent effect of leptin is appetite control [11], but it is has become increasingly clear that leptin also influences sympathetic tone and blood pressure independently of food intake. This has been shown not only in the abovementioned population studies but also in experimental studies. Intravenous application of leptin to healthy normal-weight men leads to an acute rise in muscle sympathetic nerve activity [12]. In lean rats, intravenous infusion of leptin [13-15], selective injection of leptin into the brain [16-19], or site-specific activation of leptin receptors in the dorsomedial hypothalamus [20] dose-dependently increases sympathetic nerve activity in various tissues [14, 16-19] with a concomitant increase in mean arterial blood pressure $[13,15,17-20]$. In addition to influencing blood pressure via a rise in sympathetic nervous activity, leptin has been shown to also achieve this via an increase in aldosterone levels and impaired endothelial function, especially in female mice [21].

In rodents with diet-induced obesity, inhibition of leptin receptors or deletion of these receptors significantly decreases the heart rate and systolic blood pressure [20, 22]. In accordance with these data, leptin-deficient $o b / o b$ mice $[20,23]$ and leptin-resistant $d b / d b$ mice [20] show a significantly lower mean arterial blood pressure than weight-matched dietinduced obese mice. Similar observations have also been made in humans with congenital leptin deficiency (CLD), who showed some evidence for sympathetic dysfunction [24] and slightly lower spontaneous blood pressure compared to age- and BMI-matched controls [20]. However, in the latter study, no influence on spontaneous blood pressure was seen under substitution with human recombinant leptin (data not provided) [20]. To our knowledge, no further examinations in patients with CLD have been performed so far.

Based on the abovementioned experimental results, we hypothesized that obesity-associated hypertension depends on sufficient leptin levels. We also hypothesized that leptin substitution in humans with CLD will increase blood pressure, maybe via an increase in 
von Schnurbein et al.: Leptin Deficiency and Hypertension

sympathetic tone. To test this, we performed detailed examinations with a wide panel of methods in a cohort of patients with CLD before and after substitution with human recombinant leptin (metreleptin).

\section{Subjects and Methods}

Four patients with classic CLD [25, 26], which is characterized by absence of leptin in the circulation, and 2 patients with CLD due to bioinactivity of the hormone [27] agreed to participate in the study. As published previously, patients with bioinactive leptin are biologically leptin deficient and hence show the same phenotype as patients completely lacking leptin $[27,28]$. Therefore, they will all be subsumed under CLD in this report. All 6 patients were offered the same examinations directly before substitution with metreleptin (Myalepta; Aegerion Pharmaceuticals, Cambridge, MA, USA) as well as 2-7 days (short-term) and 7-14 months (long-term) after the start of substitution. Due to typical outpatient conditions, however, not all measurements could be conducted on all patients, as some patients did not tolerate all examinations.

In addition, ambulatory blood pressure measurements were performed on 3 patients with nonfunctional leptin receptor due to biallelic disease-causing variants in the leptin receptor gene.

\section{Anthropometric Assessment and Body Composition}

The subjects were examined in light pants, a vest, and no shoes. Body weight was measured to the nearest $0.1 \mathrm{~kg}$ on a calibrated balance beam scale (Seca, Hamburg, Germany). Body height was measured to the nearest $0.1 \mathrm{~cm}$ (Ulmer Stadiometer; BUSSE Design+Engineering, Ulm, Germany). Body mass index (BMI) values were calculated as weight (in kilograms) divided by height (in meters) squared. BMI $z$-scores were calculated using German reference values, because for these reference values, $z$-scores for adults can be calculated [29]. When calculating World Health Organization BMI $z$-scores for the children [30], slightly lower $z$-scores were obtained but with the same trend. Body fat mass was assessed by dual-energy X-ray absorptiometry (Lunar Prodigy Primo; GE Healthcare, Munich, Germany).

\section{Laboratory Measurements}

Blood samples were obtained after an overnight fast by venous puncture. Blood plasma for metanephrine and normetanephrine analysis was frozen directly after withdrawal and analyzed later, whereas aldosterone analyses were performed directly. All examinations were performed by standard methods. Age-related reference values were obtained from the instructions of the commercial analysis.

\section{Blood Pressure Measurements}

Spontaneous blood pressure (mm Hg) was measured with a calibrated blood pressure monitor (Dinamap ${ }^{\mathrm{TM}}$; Critikon, GE Healthcare) on the right arm while the patients were sitting for at least $5 \mathrm{~min}$. For continuous daytime ambulatory blood pressure measurements, blood pressure was measured every 30 min during daytime with ABD monitors, version 2.6 (Spacelabs Healthcare, Snoqualmie, WA, USA), or GE TONOPORT V analysis CardioSoft v6.51 (GE Healthcare) on the right arm. The cuff widths amounted to at least $40 \%$ of the upper arm circumference. The subjects were instructed to perform their daily activities as usual, but to remain still with their arm extended and relaxed during each blood pressure measurement. The results were evaluated according to the 2016 European Society of Hypertension guidelines for children and adolescents [31]. In case of hypertension, secondary hypertension was ruled out according to these standards [31]. 


\section{Heart Rate during Resting}

Both before the Schellong test and before the cold pressor test, the heart rate was measured after 10,12, and 15 min of resting. A mean was calculated for each patient from these values.

\section{Schellong Test}

Blood pressure and heart rate were measured after 10,12, and 15 min of resting. The average results of these measurements were compared to measurements every minute while standing for $10 \mathrm{~min}$.

\section{Cold Pressor Test}

Blood pressure and heart rate were measured after 10, 12, and 15 min of resting. The average results of these measurements were compared to measurements after 30 -s and 60-s immersion of the right arm (hand up to the elbow) in cold water $\left(4^{\circ} \mathrm{C}\right)$.

\section{Heart Rate Variability}

Heart rate variability (HRV) was recorded in the morning after an overnight fast in a resting position during a 5-min ECG recording using BIOPAC MP150 data acquisition and an analysis system with AcqKnowledge software (BIOPAC Systems Inc., Goleta, CA, USA). The RR interval time series were extracted from the BIOPAC electrocardiogram data using Kubios HRV software (Mindfield Biosystems Ltd., Gronau, Germany). This software provides frequency domain parameters calculated by Welch's/Lomb-Scargle periodogram and AR spectrum estimates in absolute units or normalized (relative value of each power component in proportion to the total power minus the VLF component; see instructions of the manufacturer). Time and frequency domain HRV analyses were realized with algorithms written in MATLAB software (MATLAB release 2012b; MathWorks, Natick, MA, USA). The short-term HRV analysis was performed based on a standard approach [32] in both the time and the frequency domain.

\section{Statistical Analysis}

For the descriptive statistics, means and standard deviations (SD) were used. The Quade test was used as a pretest to identify significant changes under metreleptin substitution. This test was only used if a complete data set for the variable per patient was available. If the result of the Quade test was statistically significant, intrapatient differences before and after metreleptin substitution were analyzed with a Wilcoxon signed-rank test. For both tests, a $p$ level $<0.05$ (two-sided) was considered as statistically significant. Statistical analysis was performed using Excel and the software R 3.0.3 (March 6, 2014; R Core Team, 2014) and RStudio version 0.98.982 (RStudio, 2014).

\section{Results}

\section{Basic Data on the Patients with CLD}

Patient 1 was of Austrian origin, patients 2-4 of Pakistani origin, and patients 5 and 6 of German origin. The patients were 6.3-34.9 years old. They were all obese, but their BMI $z$-scores varied from 2.3 to 4.7 before metreleptin substitution (Table 1). Three patients presented with dyslipidemia, 3 patients had elevated transaminase levels consistent with hepatic steatosis, and 2 patients had increased fasting insulin levels (Table 1). No patient received any further medication prior to or during metreleptin substitution. 
Table 1. Participants' demographical data

\begin{tabular}{llrr}
\hline & & $n$ & $\%$ \\
\hline Gender & Male & 20 & 10.0 \\
& Female & 180 & 90.0 \\
\hline Marital status & Single & 64 & 32.0 \\
& Married & 134 & 67.0 \\
& Others & 2 & 1.0 \\
\hline Nationality & Arab & 15 & 7.5 \\
& Filipino & 85 & 42.5 \\
& Indian & 92 & 46.0 \\
& Others & 8 & 4.0 \\
\hline Level of education & Diploma & 14 & 7.0 \\
& Bachelor's & 170 & 85.0 \\
& Master's & 16 & 8.0 \\
\hline Pain management education & Yes & 125 & 62.5 \\
& No & 75 & 37.5 \\
\hline Age, years (mean \pm SD) & & $35.43 \pm 8.134$ \\
Experience, years (mean \pm SD) & & $11.88 \pm 6.289$ \\
\hline
\end{tabular}

All patients were treated with a metreleptin dose of $0.03 \mathrm{mg} / \mathrm{kg}$ lean body weight/day (based on the results of dual-energy X-ray absorptiometry). Under substitution with metreleptin, their eating behavior and satiety changed instantaneously [27]; however, the change in BMI $z$-score within the first week was no more than 0.1 (Table 2). Over the following 7-14 months of substitution, the overall decline in BMI $z$-score ranged from 0.4 to 1.8 (Table 2). For 3 patients (patients 1, 3, and 4) this led to a reduction in BMI $z$-score close to or below 2 (World Health Organization cutoff for obesity; Table 2).

\section{Continuous Daytime Ambulatory Blood Pressure Monitoring}

Before metreleptin substitution, 2 patients (patients 1 and 2) showed a normal blood pressure (Table 2). In the other 4 patients, more than $50 \%$ of the documented single systolic/ diastolic blood pressure measurements and also the average systolic and diastolic blood pressure lay above the 95th percentile for height and gender indicating hypertension (Table 2).

Short-Term Changes $(n=4)$

After 2-4 days of metreleptin substitution, the average systolic and diastolic ambulatory blood pressure increased in 3 out of 4 patients (Fig. 1A1, A2, B; Table 2). The maximum daytime values of systolic blood pressure and heart rate increased in all 4 patients (the mean max. systolic blood pressure for these 4 patients increased from $175 \pm 30$ to $197 \pm 29 \mathrm{~mm} \mathrm{Hg}$; the mean max. heart rate increased from $133 \pm 23$ to $174 \pm 21 \mathrm{bpm}$; individual data not shown).

\section{Long-Term Changes $(n=4)$}

After 7-11 months of metreleptin substitution, the average systolic and diastolic blood pressure rose above baseline in 2 patients (patients 2 and 5), despite a decrease in BMI $z$-score of 0.5 and 1.1, respectively (Fig. 2A; Table 2). In the 2 patients whose BMI $z$-score was lowered close to or below 2 within these 11 months (patients 3 and 4), the average systolic and diastolic blood pressure values fell below baseline (Fig. 2B; Table 2). 


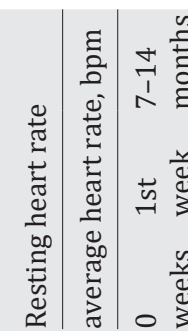

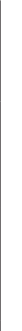

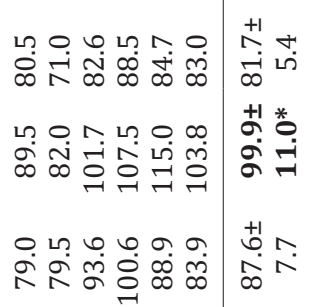

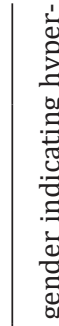

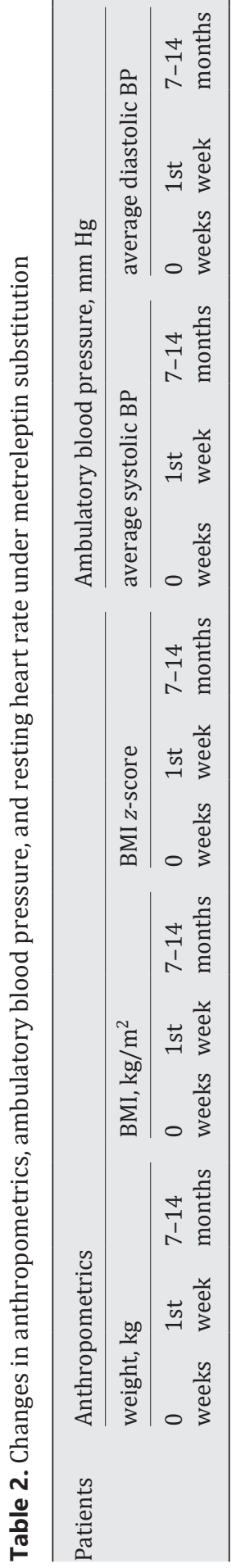

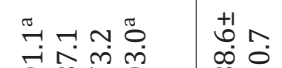

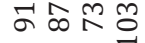
$\infty$

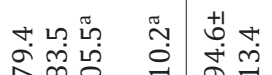

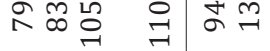

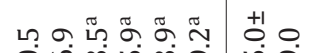

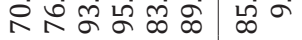

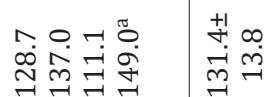

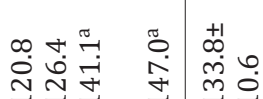
$\underset{\sim}{\sim} \underset{\sim}{\sim} \underset{\sim}{\sim} \stackrel{\sim}{\sim}$

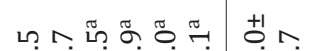

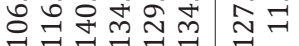

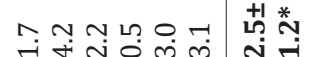
(⿻)

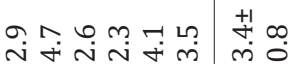

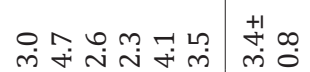

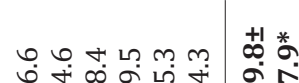
ปั่

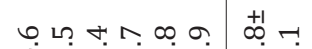

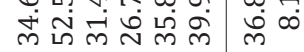

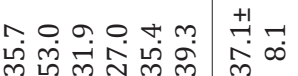

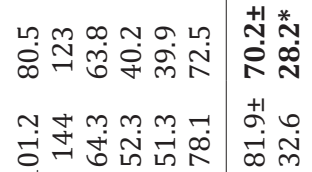
-

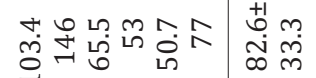

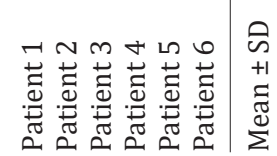

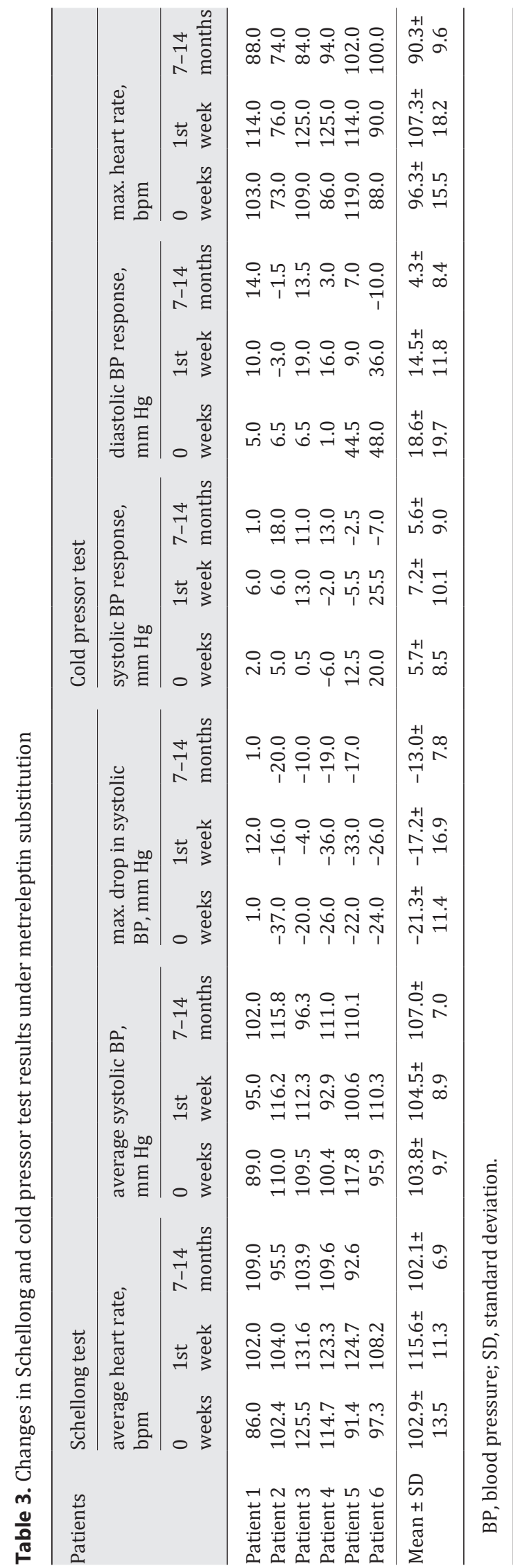



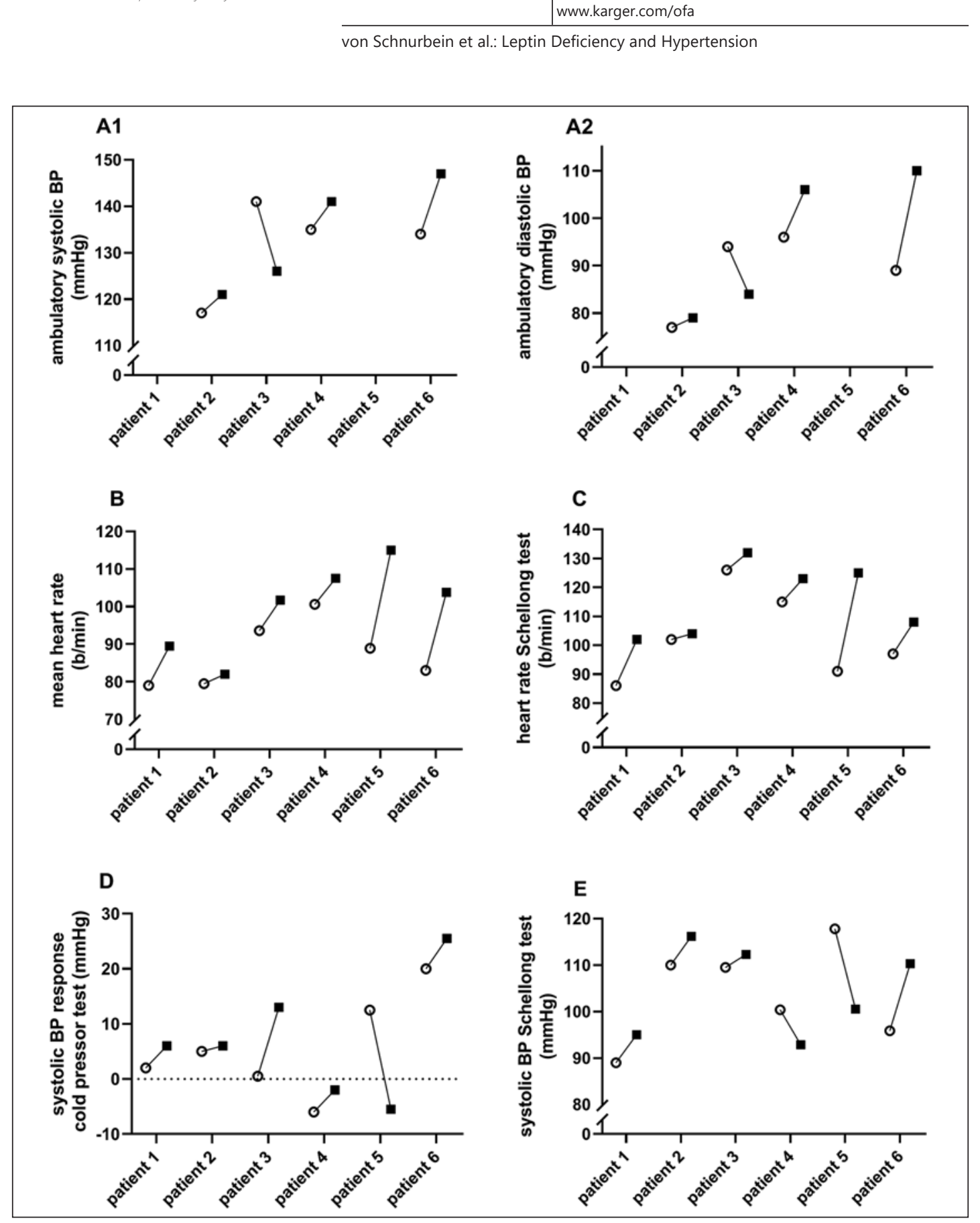

Fig. 1. Short-term changes under metreleptin substitution. The graphic shows intra-individual changes in ambulatory BP measurements (A1, A2), resting heart rate (B), heart rate during the Schellong test (C), systolic BP response during the cold pressor test (D), and systolic BP during the Schellong test (E) under 2-7 days of metreleptin substitution. White circles represent the status before, and black squares represent the status after, 2-7 days of metreleptin substitution. BP, blood pressure.

\section{Heart Rate during Resting}

Short-Term Changes $(n=6)$

Within 3-7 days of metreleptin substitution, the resting heart rate measured prior to the Schellong test and prior to the cold pressor test increased before both tests in all patients (Fig. 1B; Table 2). The mean resting heart rate of the whole group increased significantly from $87.6 \pm 7.7$ to $99.9 \pm 11.0 \mathrm{bpm}(p=0.031$; Table 2$)$. 


\section{A) Patients with a long term BMI z-score high above 2}
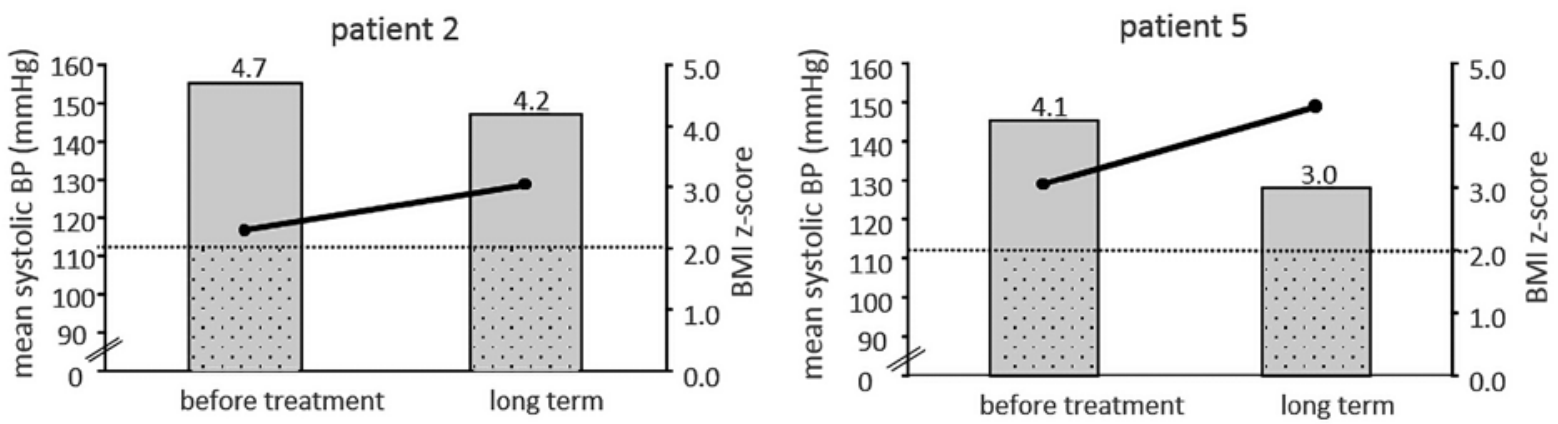

B) Patients with a long term BMI z-score close to or below 2

patient 3

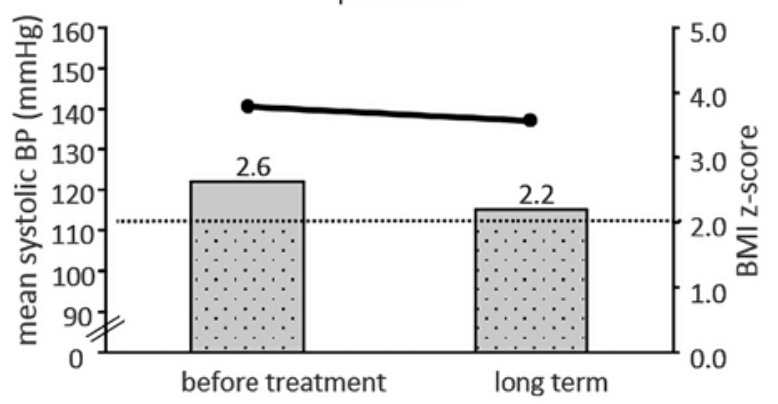

patient 4

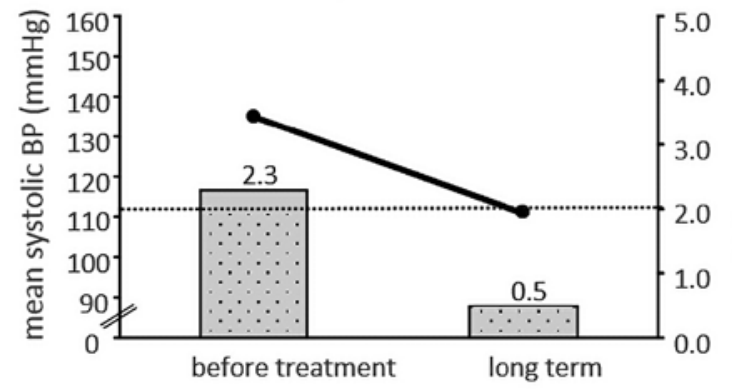

Fig. 2. Long-term changes in ambulatory daytime systolic BP under metreleptin substitution. The graphic shows intra-individual changes in ambulatory daytime systolic BP measurements compared to changes in BMI $z$-scores in the patients who remained morbidly obese (BMI $z$-score $>3$ and BMI $>35 \mathrm{~kg} / \mathrm{m}^{2}$ in the adult patient; A) or in the patients who came close to or below a BMI $z$-score of 2 (World Health Organization cutoff for overweight in children; B). The bars represent BMI $z$-scores, and points connected by lines represent the mean ambulatory systolic BP. BP, blood pressure.

Long-Term Changes ( $n=5$ [Schellong Test], $n=6$ [Cold Pressor Test])

After 7-14 months of metreleptin substitution, concomitant with a mean decrease in BMI $z$-score of $0.9 \pm 0.5$ (Table 2 ), in 4 out of 6 patients the resting heart rate fell below the baseline value (from $87.6 \pm 7.7$ to $81.7 \pm 5.4 \mathrm{bpm} ; p=0.094$; Table 2 ), and in all patients below the heart rate seen immediately after the start of therapy (from $99.9 \pm 11.0$ to $81.7 \pm 5.4 \mathrm{bpm}$; $p=0.031$; Table 2).

\section{Schellong Test}

Before metreleptin substitution, patient 3 showed a true orthostatic dysregulation with a fall in diastolic blood pressure greater than $10 \mathrm{~mm} \mathrm{Hg}$ within the first 3 min after standing up, and patients 2 and 4-6 had a pronounced systolic blood pressure drop of more than 20 mm Hg. Patient 1, however, had a normal response to the Schellong test (Table 3).

Short-Term Changes $(n=6)$

Within 3-7 days of metreleptin substitution, the average heart rate while standing increased in all 6 patients compared to baseline; however, this was not significant in the 
Quade test (Fig. 1C; increase in mean heart rate from $102.9 \pm 13.5$ to $115.6 \pm 11.3 \mathrm{bpm} ; p>$ 0.05 in the Quade test; Table 3) and the average systolic blood pressure while standing increased in 4 out of 6 patients (Fig. 1E) - again not significantly in the whole group (from $103.8 \pm 9.7$ to $104.5 \pm 8.9 \mathrm{~mm} \mathrm{Hg} ; p>0.05$ in the Quade test; Table 3 ). There was no consistent change in maximum blood pressure drop (Table 3 ).

Long-Term Changes $(n=5)$

After 7-14 months of metreleptin substitution, compared to baseline there was no consistent change in average heart rate while standing or in average systolic blood pressure (Table 3). However, in 4 out of 5 patients, the maximum drop in blood pressure decreased compared to baseline - though this change was not significant (mean systolic blood pressure drop in those 5 patients before substitution: $-21.3 \pm 12.4 \mathrm{~mm} \mathrm{Hg}$; after long-term substitution: $-13.0 \pm 7.8 \mathrm{~mm} \mathrm{Hg}$; $p>0.05$ in the Quade test; Table 3).

\section{Cold Pressor Test}

Before substitution, 4 out of 6 patients (patients 1-4) with CLD showed a low response to cold water, with a rise in systolic and diastolic blood pressure of less than $10 \mathrm{~mm} \mathrm{Hg}$ (Table $3)[24,33]$. In contrast, patients 5 and 6 showed a normal or even exaggerated response to the test, especially in diastolic blood pressure increase, as seen in other patients with hypertension [33].

Short-Term Changes ( $n=6$ )

In 5 out of 6 patients, the systolic blood pressure response (increase in systolic blood pressure from resting to cold water exposure) increased (Fig. 1D; Table 3). However, in the youngest patient, who hardly tolerated the test, a pronounced reduction in response was seen, rendering the results nonsignificant (before substitution: $5.7 \pm 8.5 \mathrm{~mm} \mathrm{Hg}$; after substitution: $7.2 \pm 10.1 \mathrm{~mm} \mathrm{Hg} ; p>0.05$ in the Quade test; Table 3). The maximum heart rate during exposure to cold water rose in 5 out of 6 patients, again without significant difference in the whole study sample (mean max. heart rate: from $96.3 \pm 15.5$ to $107.3 \pm 18.2 \mathrm{bpm} ; p>0.05$ in the Quade test; Table 3).

Long-Term Changes $(n=6)$

After 7-14 months of metreleptin substitution, no consistent change in maximum heart rate or blood pressure response compared to baseline was observed (Table 3), but the maximum heart rate fell below the heart rate seen immediately after the start of substitution in 5 out of 6 patients (after 3-7 days of substitution: $107.3 \pm 18.2 \mathrm{bpm}$; after 7-14 months of substitution: $90.3 \pm 9.6 \mathrm{bpm} ; p>0.05$ in the Quade test; Table 3).

\section{Heart Rate Variability}

Short-Term Changes $(n=5)$

In 4 out of 5 patients, total HRV - measured as the standard deviation of the normal-tonormal interval (SDNN) - decreased, while it increased in patient 6 (mean SDNN: from $32.1 \pm$ 7.1 to $35.1 \pm 13.1 ; p>0.05$ in the Quade test; Table 4). The (normalized) high-frequency component (HFn(AR), HFn(Welch), HF(AR), and HF(Welch); Table 4) also decreased in 4 out of 5 patients, while the (normalized) low-frequency component (LFn(AR), LFn(Welch), LF(AR), and LF(Welch); Table 4) and also the quotient (LFHFn(Welch)) increased in 3 out of 5 patients ( $1.75 \pm 1.5$ vs. $1.78 \pm 1.4 ; p>0.05$ in the Quade test; individual data not shown).

In general, vagal activity is the major contributor to the (n)HF component, and also increases HRV. In contrast, sympathetic influence is associated with decreased HRV. The (n)LF component is influenced by both parasympathetic and sympathetic nervous tone, 


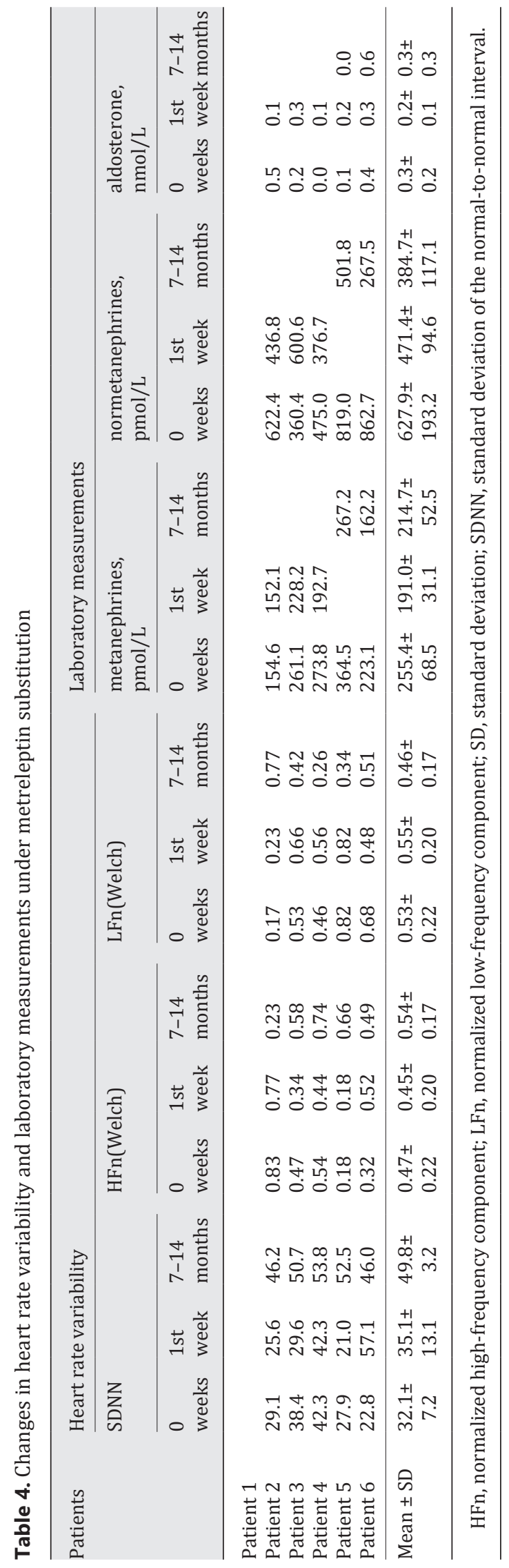


von Schnurbein et al.: Leptin Deficiency and Hypertension

and an increased LF/HF ratio indicates an increased sympathetic influence and a reduced vagal influence [32].

Thus, although none of the changes reached significance, the results indicate a tendency towards a lowering of the parasympathetic influence and an increase in the sympathetic influence.

Long-Term Changes ( $n=5)$

After 7-11 months of metreleptin substitution, HRV - measured as the SDNN - increased compared to baseline in all 5 patients; however, this was not significant (before substitution: $32.1 \pm 7.2$; after substitution: $49.8 \pm 3.2 ; p>0.05$ in the Quade test; Table 4). Both the highfrequency and the low-frequency component increased compared to baseline in all patients however, this was confirmed neither in the normalized components (Table 4) nor in the LF/ HF ratio (data not shown).

\section{Laboratory Changes}

Short-Term Changes $(n=5)$

The metanephrine values fell slightly in 2 out of 3 patients, and did not change in 1 patient (Table 4). In normetanephrine levels and aldosterone levels, no consistent changes were seen (Table 4).

In mice, leptin elicits a stronger increase in aldosterone levels in females than in males [21]. However, the change in aldosterone levels in our cohort was not higher in the female patients than in the male patients $(-0.2 \pm 0.16$ vs. $0.1 \pm 0.02 \mathrm{nmol} / \mathrm{L}$; Table 4$)$.

Long-Term Changes $(n=2)$

Long-term values were only available for 2 patients (patients 5 and 6). The metanephrine and normetanephrine levels went down in both patients (Table 4). There were no consistent changes in aldosterone (Table 4).

Findings in Patients with Disease-Causing Leptin Receptor Gene Variants

At the time of the continuous daytime ambulatory blood pressure measurement, the patients were aged 6 years (patient 1 , male, BMI $z$-score 3.9, homozygous for a deletion of exon 4-20 [NM_001003679.3]), 9 years (patient 2, male, BMI z-score 3.4, homozygous for the established disease-causing variant NM_002303.5:c.2051A >C p.[His684Pro]), and 15 years (patient 3, female, BMI $z$-score 5.3, compound heterozygous for an ENST00000349533:c.2227T >C p.[Ser743Pro] variant, and a novel 13-bp splice site deletion ENST00000349533:c.2598-3_2607delTAGAATGAAAAAG) [34].

All 3 patients showed elevated ambulatory blood pressure measurements with an average systolic blood pressure and/or at least $50 \%$ of the single systolic blood pressure measurements above the 90th percentile for gender and height (mean systolic blood pressure of all patients: $136.9 \pm 10.8 \mathrm{~mm} \mathrm{Hg}$; data not shown).

In patient 1 , the average systolic and diastolic blood pressure and more than $50 \%$ of the single systolic and diastolic blood pressure measurements lay even above the 95 th percentile for gender and height indicating hypertension (mean blood pressure of this patient: 152/100 mm Hg).

\section{Discussion}

In this study, we examined in a detailed analysis the influence of leptin deficiency and leptin substitution on blood pressure and heart rate in humans with CLD. Our first hypothesis was that leptin is an essential driver of obesity-associated hypertension. In patients with 
common obesity, leptin levels correlate positively with increased blood pressure $[8,9]$. Because patients with common obesity are resistant to the anorexic effect of leptin, the concept of a selective leptin resistance has been developed in parallel to the idea of a selective insulin resistance [35,36], implying that rising leptin levels continue to increase blood pressure while exerting no effect on satiety. Consistent with this idea, it has been observed that intracerebroventricular injection of leptin in diet-induced obese mice fails to suppress appetite while causing a dose-dependent increase in renal sympathetic nerve activity and blood pressure comparable to that in lean mice [37]. Similar observations have been made in genetically leptin-resistant Agouti Yellow mice [36]. The mechanisms behind this selective leptin resistance might entail site-specific selective leptin sensitivity in differential brain regions [20] and/or selective in/activation of distinct leptin signal transduction pathways $[38,39]$.

If a selective leptin resistance exists also in obese humans, elevated leptin levels could be responsible for obesity-associated hypertension. In that case, we would expect our patients with a complete lack of functionally active leptin to have low blood pressure despite their obesity. Contrary to our expectations, however, 4 out of the 6 patients displayed hypertension at baseline. In addition to our cohort with CLD, we had the chance to examine 3 patients with a nonfunctional leptin receptor, and also of these patients, 1 patient fulfilled the criteria for hypertension. To our knowledge, this is the first report proving - via the gold standard of ambulatory blood pressure examination - that patients with CLD or a nonfunctional leptin receptor can in fact have hypertension. This finding is important, as it contradicts the idea that leptin signaling is necessary for obesity-induced increases in blood pressure [20]. Nonetheless, our finding is in accordance with a study by Brown et al. [40], who, in a cohort of 107 patients with lipodystrophy, found that one-third of them suffered from hypertension while having very low leptin levels.

Since we can show that hyperleptinemia is not essential for obesity-associated hypertension, other mechanisms must play an important role. As stated above, various pathways have been suggested, such as mechanical compression of the kidney [2], endothelial dysfunction [3], overactivation of the renin-angiotensin system [4], elevation of aldosterone levels [5], and increased sympathetic tone [6, 7], all of which might occur independently of hyperleptinemia.

Our next hypothesis was that even if leptin is not essential for hypertension, substitution might still be able to raise the blood pressure, possibly via an increased sympathetic tone. Here, the effect of short-term metreleptin substitution is of special interest, since the results of these examinations are not yet confounded by the weight loss seen in the long-term examinations. In all patients, the mean resting heart rate and the mean heart rate during a Schellong test increased after short-term metreleptin substitution. In addition, in 4 out of 5 patients, HRV and the HF component of HRV (both parameters of parasympathetic influence) decreased, whereas the maximum heart rate during a cold pressor test increased in 5 out of 6 patients. These indicators of increased sympathetic influence were accompanied by an increase in maximum daytime systolic and diastolic blood pressure in all the examined patients, as well as in mean systolic and diastolic ambulatory blood pressure in 3 out of 4 patients.

Taken together, our results indicate that metreleptin substitution in patients with CLD can increase the heart rate and blood pressure (at least in some patients). Theoretically, this might be due to an increased sympathetic tone, as has been demonstrated for leptin-deficient $o b / o b$ mice [20], but we did not see a concomitant increase in plasma catecholamine metabolites - on the contrary, those tended to decrease. This does, however, not completely rule out an increased sympathetic influence, since not in all population studies, weight gain with increased leptin and blood pressure values has been accompanied by increased plasma catecholamine levels [40]. Based on this observation, it has been suggested that regional sympa- 
thetic nervous activity (e.g., of the kidney) might be more important for leptin's influence on blood pressure than a systemic increase in catecholamines [41] - data which are supported by the fact that renal denervation can lower blood pressure in treatment-resistant hypertension [42].

It is also conceivable that leptin increases the heart rate and blood pressure by mechanisms independent of sympathetic tone. One possible mechanism could be a direct effect of leptin on the heart, since it has been shown that at least in rats, myocytes (including those of the sinus node) express leptin receptors [43]. However, low-dose leptin [43] or leptin infusion under adrenergic blockade [15] leads to a lowering of the heart rate instead of an increase.

It has also been proposed that for blood pressure regulation by leptin there exists a sexual dimorphism. For female mice, it has been shown that, in contrast to male mice, the leptinmediated increase in blood pressure is more strongly influenced by increased aldosterone levels than by raised sympathetic tone [21]. However, in our results we did not see any femalespecific rise in aldosterone levels under metreleptin substitution. Taken together, we do not know by which mechanism short-term leptin substitution increased the resting heart rate in all of our patients, and blood pressure in some of them.

Under long-term treatment, a considerable weight loss was achieved. Concomitant with this weight loss, the increased heart rate sank; the average heart rate during resting even decreased below baseline values in 4 out of 6 patients. Despite the weight loss, the blood pressure of those patients who remained morbidly obese increased further, thereby indicating that leptin may indeed have an additive effect on obesity-associated hypertension. Since this increase in blood pressure was accompanied by a decrease in heart rate, it seems unlikely that this blood pressure increase is mediated via an increased sympathetic tone.

In contrast to this increase in blood pressure in the 2 severely obese patients, the blood pressure of the 2 patients who came close to being only overweight, or even normal weight, remained stable or decreased - despite the fact that the metreleptin substitution remained unchanged in all patients $(0.03 \mathrm{mg} / \mathrm{kg}$ lean body weight $)$. The same effect has been observed in $o b / o b$ mice, in which metreleptin substitution initially leads to increases in blood pressure and heart rate, which diminish over time in accordance with a normalization of their body weight [20]. Since neither in CLD patients nor in $o b / o b$ mice leptin levels are regulated by body adiposity, the link between improved weight and diminished blood pressure cannot be attributed to falling leptin levels, implying that other factors translate reduced weight into reduced blood pressure levels.

\section{Strengths and Limitations}

The main strength of our study is that we were able to examine changes in blood pressure and heart rate in a cohort of patients that was fairly large given the extreme rarity of CLD. In addition, we applied a wide panel of methods to be able to detect even a subtle influence of metreleptin.

Limitations of our study include that all examinations were performed under outpatient clinic conditions and we were, for example, unable to measure breathing rate during HRV. In addition, not all examinations were tolerated by all patients. Furthermore, because most of the patients were children, measurement of muscle sympathetic nerve activity was considered too invasive. These pediatric patients may also have been more excited during the beginning of their visit with us (hence, before metreleptin substitution), which might have increased their heart rate and blood pressure prior to metreleptin substitution. It is therefore remarkable that in most patients we still see an increase in heart rate and blood pressure after the beginning of metreleptin substitution. 
von Schnurbein et al.: Leptin Deficiency and Hypertension

\section{Conclusions}

Our results indicate that short-term metreleptin substitution can raise the heart rate and blood pressure not only in mice but also in obese humans lacking functional leptin. Therefore, it seems possible that leptin indeed plays a relevant role in human obesity-associated hypertension. This effect might be mediated via a regional sympathetic influence or by yet unknown mechanisms. More importantly, however, we were able to demonstrate that the development of hypertension in obese patients does not depend on the presence of leptin. This suggests that obesity-associated hypertension is caused by an intricate interwoven network of regulators among which leptin seems to have only an additive effect.

\section{Acknowledgements}

We thank the patients and their families for participating in the studies. We also thank Amylin Pharmaceuticals (San Diego, CA, USA), AstraZeneca (London, UK), Bristol-Myers Squibb (New York City, NY, USA), and Aegerion Pharmaceuticals for the provision of metreleptin.

\section{Statement of Ethics}

All examinations adhered to the principles of the Declaration of Helsinki and were approved by the Ethics Committee of the University of Ulm. They were all performed with informed parental or patient consent; the underaged patients gave informed assent in addition.

\section{Disclosure Statement}

M. Wabitsch and J. von Schnurbein have worked as consultants for Aegerion Pharmaceuticals. All other authors have nothing to disclose.

\section{Funding Sources}

J. von Schnurbein received financial support in the form of a research grant from the Hertha-Nathorff-Programm of the Medical Faculty of the University of Ulm (KSKI, 002.1).

\section{Author Contributions}

J. von Schnurbein designed the work, interpreted the data, drafted the work, final-proofed the version to be published, and is accountable for all aspects of the work; J. Manzoor substantially contributed to the conduction of the examinations, interpretation of the data, critical revision of the draft, and final approval of the published version; S. Brandt substantially contributed to the interpretation of the data, statistical analysis, critical revision of the draft, and final approval of the published version; F. Denzer substantially contributed to the interpretation of the data, critical revision of the draft, and final approval of the published version; K. Kohlsdorf substantially contributed to the conduction of the examinations, interpretation 
von Schnurbein et al.: Leptin Deficiency and Hypertension

of the data, critical revision of the draft, and final approval of the published version; P. FischerPosovszky substantially contributed to the interpretation of the data, critical revision of the draft, and final approval of the published version; M. Weißenberger, S. Frank-Podlech, and S. Mahmood substantially contributed to the conduction of the examinations, interpretation of the data, critical revision of the draft, and final approval of the published version; M. Wabitsch designed the work, interpreted the data, drafted the work, final-proofed the version to be published, and is accountable for all aspects of the work.

\section{References}

1 Landsberg L, Aronne LJ, Beilin LJ, Burke V, Igel LI, Lloyd-Jones D, et al. Obesity-related hypertension: pathogenesis, cardiovascular risk, and treatment - a position paper of the The Obesity Society and The American Society of Hypertension. Obesity (Silver Spring). 2013 Jan;21(1):8-24.

2 Sugerman $\mathrm{H}$, Windsor A, Bessos M, Wolfe L. Intra-abdominal pressure, sagittal abdominal diameter and obesity comorbidity. J Intern Med. 1997 Jan;241(1):71-9.

3 Raitakari M, Ilvonen T, Ahotupa M, Lehtimäki T, Harmoinen A, Suominen P, et al. Weight reduction with verylow-caloric diet and endothelial function in overweight adults: role of plasma glucose. Arterioscler Thromb Vasc Biol. 2004 Jan;24(1):124-8.

4 Reisin E, Weir MR, Falkner B, Hutchinson HG, Anzalone DA, Tuck ML; Treatment in Obese Patients with Hypertension (TROPHY) Study Group. Lisinopril versus hydrochlorothiazide in obese hypertensive patients: a multicenter placebo-controlled trial. Hypertension. 1997 Jul;30(1 Pt 1):140-5.

5 de Souza F, Muxfeldt E, Fiszman R, Salles G. Efficacy of spironolactone therapy in patients with true resistant hypertension. Hypertension. 2010 Jan;55(1):147-52.

6 Troisi RJ, Weiss ST, Parker DR, Sparrow D, Young JB, Landsberg L. Relation of obesity and diet to sympathetic nervous system activity. Hypertension. 1991 May;17(5):669-77.

7 Sowers JR, Nyby M, Stern N, Beck F, Baron S, Catania R, et al. Blood pressure and hormone changes associated with weight reduction in the obese. Hypertension. 1982 Sep-Oct;4(5):686-91.

8 Shankar A, Xiao J. Positive relationship between plasma leptin level and hypertension. Hypertension. 2010 Oct;56(4):623-8.

9 Asferg C, Møgelvang R, Flyvbjerg A, Frystyk J, Jensen JS, Marott JL, et al. Leptin, not adiponectin, predicts hypertension in the Copenhagen City Heart Study. Am J Hypertens. 2010 Mar;23(3):327-33.

10 Frederich RC, Hamann A, Anderson S, Löllmann B, Lowell BB, Flier JS. Leptin levels reflect body lipid content in mice: evidence for diet-induced resistance to leptin action. Nat Med. 1995 Dec;1(12):1311-4.

11 Grill HJ, Schwartz MW, Kaplan JM, Foxhall JS, Breininger J, Baskin DG. Evidence that the caudal brainstem is a target for the inhibitory effect of leptin on food intake. Endocrinology. 2002 Jan;143(1):239-46.

12 Machleidt F, Simon P, Krapalis AF, Hallschmid M, Lehnert H, Sayk F. Experimental hyperleptinemia acutely increases vasoconstrictory sympathetic nerve activity in healthy humans. J Clin Endocrinol Metab. 2013 Mar; 98(3):E491-6.

13 Shek EW, Brands MW, Hall JE. Chronic leptin infusion increases arterial pressure. Hypertension. 1998 Jan; 31(1 Pt 2):409-14.

14 Haynes WG, Morgan DA, Walsh SA, Mark AL, Sivitz WI. Receptor-mediated regional sympathetic nerve activation by leptin. J Clin Invest. 1997 Jul;100(2):270-8.

15 Carlyle M, Jones OB, Kuo JJ, Hall JE. Chronic cardiovascular and renal actions of leptin: role of adrenergic activity. Hypertension. 2002 Feb;39(2 Pt 2):496-501.

16 Dunbar JC, Lu H. Leptin-induced increase in sympathetic nervous and cardiovascular tone is mediated by proopiomelanocortin (POMC) products. Brain Res Bull. 1999 Oct;50(3):215-21.

17 Dunbar JC, Hu Y, Lu H. Intracerebroventricular leptin increases lumbar and renal sympathetic nerve activity and blood pressure in normal rats. Diabetes. 1997 Dec;46(12):2040-3.

18 Rahmouni K, Morgan DA. Hypothalamic arcuate nucleus mediates the sympathetic and arterial pressure responses to leptin. Hypertension. 2007 Mar;49(3):647-52.

19 Mark AL, Agassandian K, Morgan DA, Liu X, Cassell MD, Rahmouni K. Leptin signaling in the nucleus tractus solitarii increases sympathetic nerve activity to the kidney. Hypertension. 2009 Feb;53(2):375-80.

20 Simonds SE, Pryor JT, Ravussin E, Greenway FL, Dileone R, Allen AM, et al. Leptin mediates the increase in blood pressure associated with obesity. Cell. 2014 Dec;159(6):1404-16.

21 Huby AC, Otvos L Jr, Belin de Chantemèle EJ. Leptin Induces Hypertension and Endothelial Dysfunction via Aldosterone-Dependent Mechanisms in Obese Female Mice. Hypertension. 2016 May;67(5):1020-8.

22 Lim K, Burke SL, Head GA. Obesity-related hypertension and the role of insulin and leptin in high-fat-fed rabbits. Hypertension. 2013 Mar;61(3):628-34.

23 Mark AL, Shaffer RA, Correia ML, Morgan DA, Sigmund CD, Haynes WG. Contrasting blood pressure effects of obesity in leptin-deficient ob/ob mice and agouti yellow obese mice. J Hypertens. 1999 Dec;17(12 Pt 2):194953. 
von Schnurbein et al.: Leptin Deficiency and Hypertension

24 Ozata M, Ozdemir IC, Licinio J. Human leptin deficiency caused by a missense mutation: multiple endocrine defects, decreased sympathetic tone, and immune system dysfunction indicate new targets for leptin action, greater central than peripheral resistance to the effects of leptin, and spontaneous correction of leptinmediated defects. J Clin Endocrinol Metab. 1999 Oct;84(10):3686-95.

25 Fischer-Posovszky P, Funcke JB, Wabitsch M. Biologically inactive leptin and early-onset extreme obesity. N Engl J Med. 2015 Mar;372(13):1266-7.

26 Fischer-Posovszky P, von Schnurbein J, Moepps B, Lahr G, Strauss G, Barth TF, et al. A new missense mutation in the leptin gene causes mild obesity and hypogonadism without affecting T cell responsiveness. J Clin Endocrinol Metab. 2010 Jun; 95(6):2836-40.

27 Wabitsch M, Funcke JB, von Schnurbein J, Denzer F, Lahr G, Mazen I, et al. Severe Early-Onset Obesity due to Bioinactive Leptin Caused by a p.N103K Mutation in the Leptin Gene. J Clin Endocrinol Metab. 2015 Sep; 100(9):3227-30.

28 Wabitsch M, Funcke JB, Lennerz B, Kuhnle-Krahl U, Lahr G, Debatin KM, et al. Biologically inactive leptin and early-onset extreme obesity. N Engl J Med. 2015 Jan;372(1):48-54.

29 Kromeyer-Hauschild K, Wabitsch M, Kunze D, Geller F, Geiß HC, Hesse V, et al. Perzentile für den Body-massIndex für das Kindes- und Jugendalter unter Heranziehung verschiedener deutscher Stichproben. Monatsschr Kinderheilkd. 2001 Aug;149(8):807-18.

30 de Onis M, Onyango AW, Borghi E, Siyam A, Nishida C, Siekmann J. Development of a WHO growth reference for school-aged children and adolescents. Bull World Health Organ. 2007 Sep;85(9):660-7.

31 Lurbe E, Agabiti-Rosei E, Cruickshank JK, Dominiczak A, Erdine S, Hirth A, et al. 2016 European Society of Hypertension guidelines for the management of high blood pressure in children and adolescents. J Hypertens. 2016 Oct;34(10):1887-920.

32 Malik M; Task Force of the European Society of Cardiology and the North American Society of Pacing and Electrophysiology. Heart rate variability: standards of measurement, physiological interpretation and clinical use. Circulation. 1996 Mar;93(5):1043-65.

33 Hines EA Jr, Brown GE. The cold pressor test for measuring the reactibility of the blood pressure: data concerning 571 normal and hypertensive subjects. Am Heart J. 1936;11(1):1-9.

34 Nunziata A, Funcke JB, Borck G, von Schnurbein J, Brandt S, Lennerz B, et al. Functional and Phenotypic Characteristics of Human Leptin Receptor Mutations. J Endocr Soc. 2018 Sep;3(1):27-41.

35 Enriori PJ, Sinnayah P, Simonds SE, Garcia Rudaz C, Cowley MA. Leptin action in the dorsomedial hypothalamus increases sympathetic tone to brown adipose tissue in spite of systemic leptin resistance. J Neurosci. 2011 Aug;31(34):12189-97.

36 Correia ML, Haynes WG, Rahmouni K, Morgan DA, Sivitz WI, Mark AL. The concept of selective leptin resistance: evidence from agouti yellow obese mice. Diabetes. 2002 Feb;51(2):439-42.

37 Rahmouni K, Morgan DA, Morgan GM, Mark AL, Haynes WG. Role of selective leptin resistance in diet-induced obesity hypertension. Diabetes. 2005 Jul;54(7):2012-8.

38 do Carmo JM, da Silva AA, Ebaady SE, Sessums PO, Abraham RS, Elmquist JK, et al. Shp2 signaling in POMC neurons is important for leptin's actions on blood pressure, energy balance, and glucose regulation. Am J Physiol Regul Integr Comp Physiol. 2014 Dec;307(12):R1438-47.

39 Morgan DA, Thedens DR, Weiss R, Rahmouni K. Mechanisms mediating renal sympathetic activation to leptin in obesity. Am J Physiol Regul Integr Comp Physiol. 2008 Dec;295(6):R1730-6.

40 Brown RJ, Meehan CA, Gorden P. Leptin Does Not Mediate Hypertension Associated with Human Obesity. Cell. 2015 Jul;162(3):465-6.

41 Vaz M, Jennings G, Turner A, Cox H, Lambert G, Esler M. Regional sympathetic nervous activity and oxygen consumption in obese normotensive human subjects. Circulation. 1997 Nov; 96(10):3423-9.

42 Hering D, Marusic P, Walton AS, Lambert EA, Krum H, Narkiewicz K, et al. Sustained sympathetic and blood pressure reduction 1 year after renal denervation in patients with resistant hypertension. Hypertension. 2014 Jul;64(1):118-24.

43 Lin YC, Huang J, Hileman S, Martin KH, Hull R, Davis M, et al. Leptin decreases heart rate associated with increased ventricular repolarization via its receptor. Am J Physiol Heart Circ Physiol. 2015 Nov; 309(10):H1731-9. 